\title{
Promoting vascular healing using nanofibrous ticagrelor-eluting stents
}

This article was published in the following Dove Press journal:

International Journal of Nanomedicine

\author{
Cheng-Hung Lee' \\ Ming-Jer Hsieh' \\ Kuo-Sheng Liư ${ }^{2,3}$ \\ Che-Wei Cheng ${ }^{3}$ \\ Shang-Hung Chang' \\ Shih-Jung $\mathrm{Liu}^{3,4}$ \\ Chao-Jan Wang ${ }^{5}$ \\ Ming-Yi Hsu ${ }^{5}$ \\ Kuo-Chun Hung' \\ Yung-Hsin Yeh' \\ Wei-Jan Chen' \\ I-Chang Hsieh' \\ Jyuhn-Huarng Juang ${ }^{6}$ \\ Ming-Shien Wen' \\ 'Division of Cardiology, Department \\ of Internal Medicine, Chang Gung \\ Memorial Hospital, Linkou, Chang \\ Gung University College of Medicine, \\ Tao-Yuan, Taiwan; ${ }^{2}$ Department of \\ Cardiovascular Surgery, Chang Gung \\ Memorial Hospital-Linkou, Tao-Yuan, \\ Taiwan; ${ }^{3}$ Department of Mechanical \\ Engineering, Chang Gung University, \\ Tao-Yuan, Taiwan; ${ }^{4}$ Department of \\ Orthopedic Surgery, Chang Gung \\ Memorial Hospital, Tao-Yuan, Taiwan; \\ ${ }^{5}$ Department of Medical Imaging and \\ Intervention, Chang Gung Memorial \\ Hospital, Linkou, Tao-Yuan, Taiwan; \\ ${ }^{6}$ Division of Endocrinology and \\ Metabolism, Department of Internal \\ Medicine, Chang Gung University \\ and Chang Gung Memorial Hospital, \\ Tao-Yuan, Taiwan
}

Correspondence: Shih-Jung Liu Biomaterials Lab, Mechanical Engineering, Chang Gung University, 259, Wen-Hwa Ist Road, Kwei-Shan, Tao-Yuan 333, Taiwan

Tel +88632 I। 8166

Fax +88632 II 8558

Email shihjung@mail.cgu.edu.tw
Objective: The current treatment of atherosclerotic coronary heart disease with limus-eluting stents can lead to incomplete endothelialization and substantial impairment of arterial healing relative to treatment with bare-metal stents. The sustained and local delivery of ticagrelor, a reversibly binding P2Y12 receptor inhibitor, using hybrid biodegradable nanofibers/stents, was developed to reduce neointimal formation and endothelial dysfunction.

Methods: In this investigation, a solution of ticagrelor, poly(D,L)-lactide-co-glycolide, and hexafluoro isopropanol was electrospun to fabricate ticagrelor-eluting nanofibrous drug-eluting stents. The in vitro and in vivo ticagrelor concentrations were measured using a high-performance liquid chromatography assay. The effectiveness of ticagrelor-eluting stents was examined relative to that of sirolimus-eluting stents.

Results: Adequate ticagrelor levels were detected for four weeks in vitro. Less HES5-positive labeling was found near the ticagrelor-eluting stented vessels $(0.33 \pm 0.12)$ than close to the sirolimus-eluting stented vessels $(0.57 \pm 0.15)(p<0.05)$. Four weeks after deployment, the ticagrelor-eluting stent also exhibited an up-regulated local expression of SOD1 in the stenting area $(p<0.001)$. The ticagrelor-eluting stent substantially preserved endothelial function and reendothelialization, minimized inflammatory responses, and inhibited neointimal hyperplasia. Conclusion: Ticagrelor-eluting stents may provide an alternative route for treating patients at a high risk of bleeding to preserve endothelial recovery and to reduce smooth muscle proliferation.

Keywords: ticagrelor, drug-eluting stents, electrospinning, endothelialization, neointimal hyperplasia

\section{Introduction}

Several prototypical antiproliferative agents have strong antimitotic properties that effectively prevent smooth muscle (SMC) proliferation and matrix formation and thus reduce neointimal development and in-stent restenosis. ${ }^{1,2}$ Although the use of drugeluting stents (DES) can reduce neointimal proliferation and restenosis, some concerns about the risk of stent thrombosis as a result of inadequate platelet inhibition, fibrin deposition, inflammation cell infiltration, incomplete re-endothelialization and inhibition of vascular repair, have arisen. ${ }^{3-5}$ Additionally, DES platforms that utilize various non-erodable polymeric coatings for drug delivery exhibit various responses with respect to thrombogenicity, immunogenicity and biological compatibility. ${ }^{6}$ Therefore, a stent that inhibits neointimal formation, preserves post-procedural endothelialization, and reduces the incidence of polymer-induced inflammation is highly desired.

Ticagrelor is an antiplatelet agent that reversibly inhibits the P2Y12 receptors on platelets and thereby ADP-induced platelet activation. Additionally, ticagrelor has been linked to improvements in peripheral endothelial function and the inhibition of both SMC proliferation and intimal hyperplasia. ${ }^{7-11}$ Hence, drug delivery using stents 
can be hypothesized to favor the local release of ticagrelor to the target site and to minimize possible systemic side effects or drug-drug interactions. ${ }^{12,13}$

This work develops poly(D,L)-lactide-co-glycolide (PLGA) nanofiber-loaded stents that locally deliver ticagrelor to injured arterial walls. PLGA is a non-cytotoxic and synthesized biodegradable copolymer, which can be absorbed over time without accumulating in the vital organs. ${ }^{14,15}$ PLGA can be degraded to form glycolic and lactic acids with a minimal inflammatory reaction. ${ }^{16}$ This process reduces the risk of any long-term effects of the non-erodable polymers on the arterial wall. ${ }^{17-19}$

The in vitro and in vivo release rates of the nanofiberloaded ticagrelor were measured using a high-performance liquid chromatography (HPLC) assay. The efficiency of the local release of ticagrelor in inhibiting platelet activation was evaluated. The inflammation of the tissue that was caused by the hybrid stents was also investigated. The effects of drug loading on the preservation of endothelial cell re-growth and functional recovery, and on the inhibition of neointima formation were examined using rabbit models. The efficacy of ticagrelor was also compared to that of sirolimus, an anti-SMCproliferative agent that causes $G_{1}$ to $S$ cell cycle arrest and prevents intimal hyperplasia following vascular injury. ${ }^{20}$

\section{Materials and method}

\section{Fabrication of ticagrelor-eluting nanofibrous tubes}

Commercially available PLGA (Resomer RG 503; lactide: glycolide ratio of 50:50) was obtained from Boehringer Ingelheim (Ingleheim, Germany). Ticagrelor was kindly provided by AstraZeneca U.K. Ltd. (London, UK), sirolimus and hexafluoro isopropanol (HFIP) was from Sigma-Aldrich (Saint Louis, MO, USA). To electrospin the nanofibers, ${ }^{21}$ PLGA/ticagrelor (high dose loading: 240/40 mg, w/w; low dose loading: 240/20 mg, w/w) and PLGA/sirolimus $(240 / 40 \mathrm{mg}, \mathrm{w} / \mathrm{w})$ in a pre-set weight ratio were firstly dissolved in $1 \mathrm{~mL}$ of HFIP. Electrospinning was conducted at $25^{\circ} \mathrm{C}$. The electrospun drug-loaded nanofibrous tube was installed on a Gazella bare metal stent $(3.5 \times 20 \mathrm{~mm}$, Biosensors International, Morges, Switzerland). To evaporate the solvents, the fabricated stent was placed in a vacuum oven (at $40^{\circ} \mathrm{C}$ for 3 days).

\section{Mechanical properties and contact angle of water}

The mechanical properties of nanofibrous membranes that were loaded with two doses of ticagrelor (high and low drug loadings) were evaluated using a Lloyd tensiometer (AMETEK, Berwyn, PA, USA) with the ASTM D638 standard. $^{22}$

Tensile strength $(\mathrm{MPa})$

$$
=\frac{\text { Breaking force }(\mathrm{N})}{\text { Cross-sectional area of sample }\left(\mathrm{mm}^{2}\right)}
$$

Elongation at breakage (\%)

$$
=\frac{\text { Increase in length at breaking point }(\mathrm{mm})}{\text { Original length }(\mathrm{mm})} \times 100 \%
$$

The water contact angles of the nanofibers, in which were embedded high and low doses of ticagrelor, were determined using an analyzer (First Ten Angstroms, Portsmouth, VA, USA). ${ }^{23}$

\section{In vitro and in vivo release}

The in vitro release properties of ticagrelor from the nanofibers were determined using an elution process for 30 days. Samples with a diameter of $3.5 \mathrm{~mm}$, a length of $20 \mathrm{~mm}$ with two ticagrelor loadings (low and high doses) were put in glass test tubes $(\mathrm{n}=3)$ with $1 \mathrm{~mL}$ of PBS.

Ticagrelor concentrations were obtained by performing an HPLC assay using a Hitachi L-2200 Multisolvent Delivery System. A Hypersil BDS C18 column $(100 \times 4.6$ mm, $5 \mu \mathrm{m})$ was used to separate out the ticagrelor. ${ }^{24}$ Blood samples of $100 \mu \mathrm{L}$ were collected from rabbits $(\mathrm{n}=9)$ on days 7,14 , 21 , and 28 days after they had been stented, in tubes that contained an anticoagulant. Plasma was prepared within 30 minutes of blood sampling by centrifugation at $1,500 \times \mathrm{g}$ for 10 minutes at $4{ }^{\circ} \mathrm{C}$. The lower limit of quantification (LLOQ) of the method was $0.00503 \mu \mathrm{M}$.

\section{Effect of ticagrelor-eluting nanofibers on platelet adhesion in vitro}

Platelet-rich plasma (PRP) $\left(2 \times 10^{5}\right.$ cells $\left./ \mu \mathrm{L}\right)$ was obtained from healthy rabbits and centrifuged ( $150 \times g$ for 10 minutes). A platelet suspension that contained $10^{7}$ platelets was then dripped onto the nanofibers (with high, low and no ticagrelor loadings), ${ }^{25}$ and incubated at $37^{\circ} \mathrm{C}$ for 180 minutes.

\section{Surgical procedure and animal care}

Twenty-four male New Zealand White rabbits $(3.0 \pm 0.5 \mathrm{~kg})$ were used in an in vivo study. All animal procedures were institutionally approved by the Committee of the Chang Gung University (Approval Number CGU 14-208), and all of the animals were cared for in a manner consistent with 
the regulations of the National Institute of Health of Taiwan under the supervision of a licensed veterinarian.

Rabbits were firstly sedated and anesthetized using inhalational anesthesia with $1 \%-3 \%$ isoflurane (Baxter International Inc., Deerfield, IL, USA) and oxygen ( $2 \mathrm{~L} / \mathrm{min})$ through a face mask. ${ }^{26}$ The rabbit aorta for stent implantation was used because of its diameter and the patency of small arterial branches mimicked the coronary artery (both of which are around $3.0 \mathrm{~mm}) .{ }^{27,28}$ Using the puncture technique, a 5 French sheath was inserted into the femoral artery. Briefly, the vessel was located by arterial palpation. The overlying skin was prepared with chlorhexidine before a small nick was made in the skin at the site of needle entry. The femoral artery was punctured and the needle was advanced slowly until a pulsating blood flow was noted. After a guidewire had been deployed, the needle was removed over the wire and a $5 \mathrm{~F}$ catheter was advanced over the guidewire into the vessel. The guidewire was then removed, leaving the catheter in place. Finally, the success of artery cannulation was confirmed by observing the pulsatile blood flow from the catheter.

Hybrid stents on which were mounted ticagrelor-eluting nanofibers were employed for the in vivo animal studies. For simplicity, nanofibers were loaded with a high dose of ticagrelor. The rabbits were separated into two groups. The ticagrelor group consisted of 12 rabbits, as did the sirolimus group. All rabbits received ticagrelor or sirolimus-eluting nanofibrous stents. They underwent endothelial denudation to induce angioplastic balloon damage. ${ }^{29-31}$ All animals received aspirin (40 $\mathrm{mg} /$ day) that was given orally 1 day before catheterization and per day after. Following stent implantation, written records of any clinical or behavior changes, daily body weight, hydration status, food and fluid consumption, were maintained for each animal. Ketoprofen ( $2 \mathrm{mg} / \mathrm{kg}$ ) was subcutaneously injected twice with a 12-hour interval for post-surgery pain relief.

\section{In vivo evaluation of endothelial function}

On day 28, the non-stented segments of the abdominal aorta $(5-10 \mathrm{~mm})$ were evaluated for endothelium-dependent vasomotor function after the infusion of two doses of acetylcholine (Ach, 0.05 and $0.5 \mu \mathrm{g} / \mathrm{mL} / \mathrm{min}$ ) through a marginal ear vein. ${ }^{32}$

Anesthetized animals were exsanguinated 4 weeks after stenting. Areas close to the ticagrelor-eluting and sirolimuseluting stented vessels were prepared for immunofluorescence analysis.

\section{Scanning electron microscope (SEM)}

Photographs at a magnification of $\times 40$ were taken to estimate the degree of endothelialization of the implant. The images were further magnified ( $\times 200$ magnification) to visualize the endothelial cells. The coverage of the endothelial surface above the stent struts was measured using Image J imaging software (National Institutes of Health, Bethesda, MD, USA). ${ }^{33}$

\section{Histological examination and characterization}

Inflammation and vascular injury scores were used herein. ${ }^{34,35}$ Scores for all struts at 4 weeks were averaged to yield mean scores $(n=24)$.

\section{Immunofluorescence}

The primary antibodies against HES5, secondary Cy3conjugated antibodies (Chemicon International, Temecula, CA, USA), were diluted in blocking solution. Nuclei were visualized by staining with DAPI $(n=3)$.

\section{Western blot analysis}

Western blotting was carried out using $20 \mu \mathrm{g}$ of protein that was loaded onto $12 \%$ Sodium dodecyl sulfate polyacrylamide gel electrophoresis (SDS-Page) gels and transferred to polyvinylidene difluoride membranes. After blotting, membranes were blocked with Tris-buffered saline, containing $0.1 \%$ Tween $20 \%$ and $2 \%$ BSA, for 1 hour at room temperature, and then incubated overnight at $4{ }^{\circ} \mathrm{C}$ with anti-superoxide dismutase 1 antibodies (ab13498) (SOD1) (Abcam, Cambridge, MA, USA) as primary antibodies. The amount of protein of interest was expressed relative to that of glyceraldehyde-3phosphate dehydrogenase (GAPDH).

\section{Statistics and data analysis}

All data are presented as mean \pm SD. One-way analysis of variance was performed to identify statistically significant differences among groups (normal distribution). Within ANOVA, a post hoc Bonferroni procedure for multiple comparisons was used to detect significant differences between pairs. In the absence of a normal distribution, non-parametric criteria were used. Differences are considered to be statistically significant at $P<0.05$. SPSS software (version 17.0 for Windows; SPSS Inc, Chicago, IL, USA) was used to analyze the data.

\section{Results}

\section{In vitro evaluation}

Loaded ticagrelor-eluting and sirolimus-eluting stents loaded were fabricated by electrospinning. Figure 1 presents SEM micrographs, with a magnification of $3,000 \times$, of the electrospun nanofibrous membrane with a high ticagrelor load (Figure 1A), a low ticagrelor load (Figure 1B), and sirolimus (Figure 1C). A significant variation in the diameter of the nanofibers among the three groups was identified 

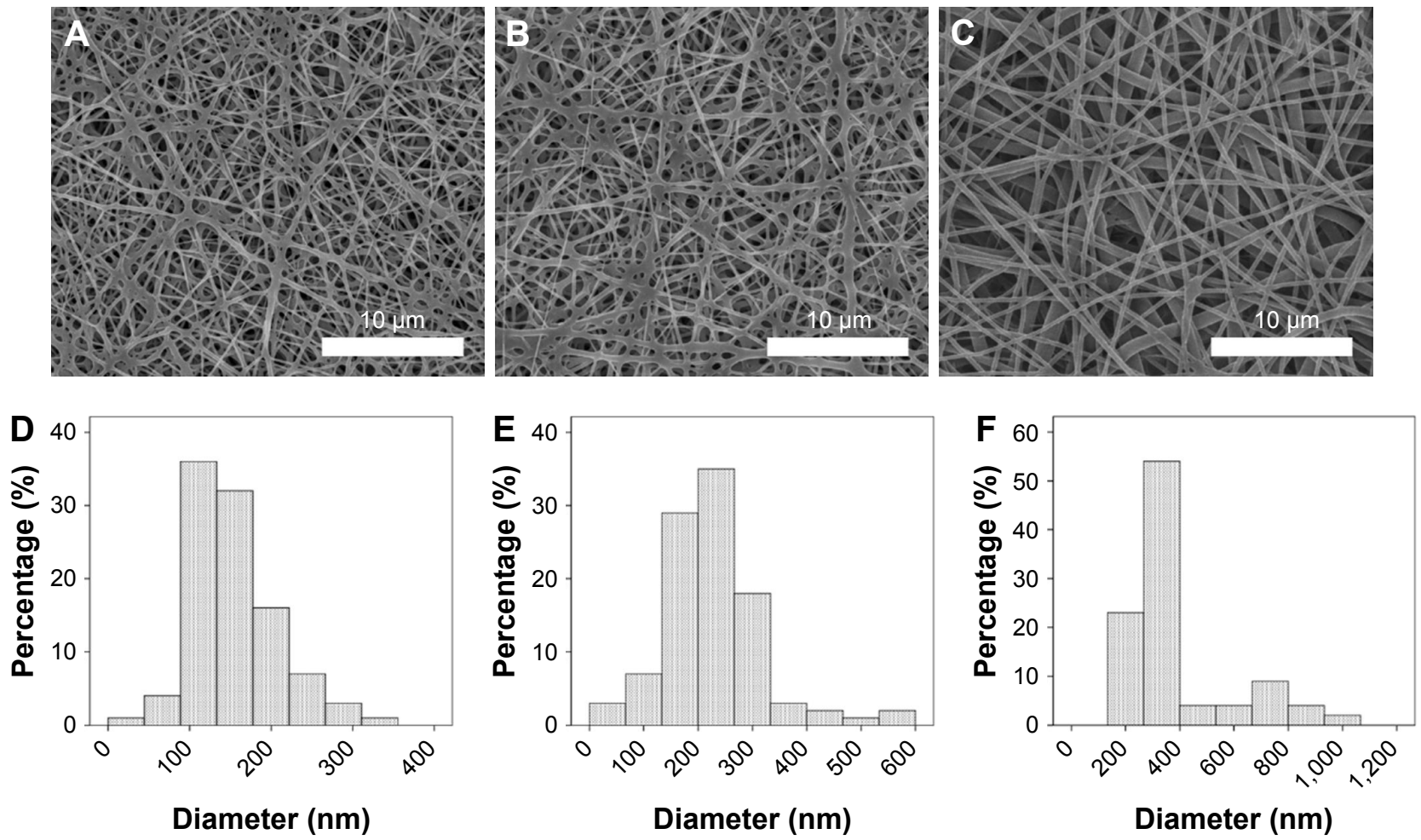

Figure I SEM micrographs, at a magnification of 3,000x

Notes: (A) Electrospun nanofibrous membrane with ticagrelor dose I. (B) Ticagrelor dose 2, and (C) sirolimus (scale bars = $10 \mu \mathrm{m})$. (D-F) The distribution of nanofiber diameters.

Abbreviation: SEM, scanning electron microscope.

(Figure 1D: high ticagrelor loading: $152.1 \pm 53.4 \mathrm{~nm}$; Figure 1E: low ticagrelor loading: $227.4 \pm 91.3 \mathrm{~nm}$; Figure 1F: sirolimus $388.0 \pm 198.0 \mathrm{~nm}$, all ANOVA $P<0.001$ ). The coefficients of variance of diameter distribution (ratio of SD to mean value) were $35.1 \%, 40.2 \%$, and $51 \%$, respectively.

Figure $2 \mathrm{~A}$ indicates that the tensile strength of nanofibers that were loaded with a high ticagrelor dose $(4.50 \pm 0.10 \mathrm{MPa})$ exceeded that of those that were loaded with a low ticagrelor dose $(3.88 \pm 0.23 \mathrm{MPa})(P=0.013)$. After they had been rinsed in PBS for 30 seconds, the nanofibers with both high and low ticagrelor loadings exhibited remarkably increased strain and reduced tensile strength (high loading: $392 \% \pm 22 \%$ and $2.23 \pm 0.21 \mathrm{MPa}$, low loading: $320 \% \pm 15 \%$ and $1.62 \pm 0.15 \mathrm{MPa}$ ). The experimental results in Figure $2 \mathrm{~B}$ and $\mathrm{C}$ also suggest that the water contact angle of the electrospun nanofibers decreased as the ticagrelor loading increased. Following the deployment of the drug-loaded stents (Figure 2D-F), the coverage by nanofiber membranes remained intact completely (Figure 2G).

Figure 3 shows the $\%$ accumulated release of ticagrelor from the drug-eluting nanofibrous membranes. The measured data suggest that the ticagrelor-eluting stents exhibited continuous drug release for 3 days following an initial burst release (reaching $33.4 \% \pm 2.9 \%$ and $32.0 \% \pm 2.0 \%$ for high and low loadings, respectively), followed by a gradually decline to $50 \%$ of the drug release at 10 days $(62.0 \% \pm 5.0 \%$ and $55.8 \% \pm 2.9 \%$ for high and low loadings, respectively) and $90 \%$ at 28 days. The in vivo ticagrelor level around the stented part with high drug loading was measured to be $555 \pm 45 \mu \mathrm{g} / \mathrm{mL}$. Additionally, values of plasma ticagrelor level below the LLOQ were noted.

The effectiveness of nanofibrous membranes, with high, low and no ticagrelor loading, against platelet adhesion was determined by SEM. The microphotographs in Figure 4 demonstrate that the ticagrelor that was released from the highly loaded nanofibers inhibited the adhesion of platelets. Remarkably fewer platelets adhered to the nanofibers with the high ticagrelor loading than to those with the low ticagrelor loading or with no loading $\left(2.1 \pm 0.4\right.$ vs $3.4 \pm 0.3 / \mu \mathrm{m}^{2}$ vs $6.3 \pm 0.2 \times 10^{3}$ activated platelets $/ \mu \mathrm{m}^{2}$, all $P<0.001$ ).

\section{In vivo assessment of endothelial morphology and function}

Based on the in vitro results, high-dose ticagrelor-eluting stents were used in the subsequent animal study. In vivo studies were performed by deploying 12 stents that were loaded with ticagrelor biodegradable nanofibers and 12 stents 

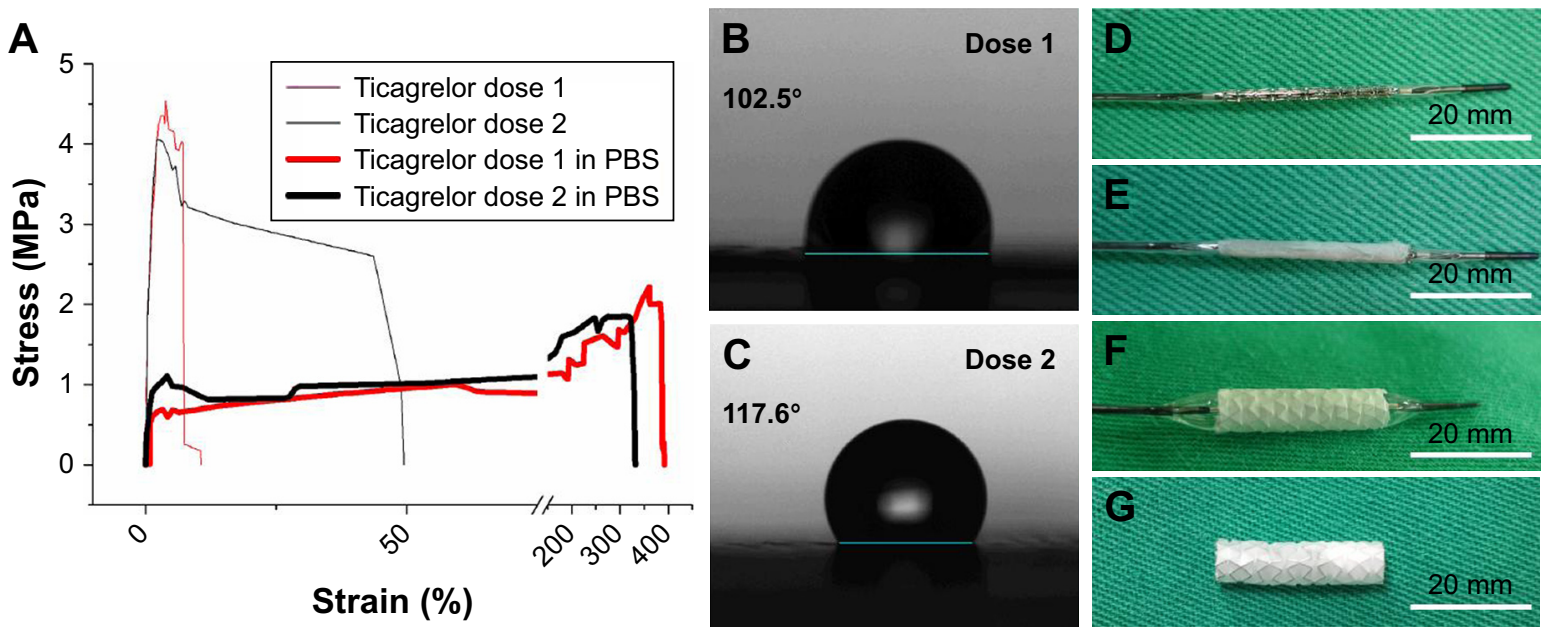

Figure 2 (A) Stress-strain curve of ticagrelor-eluting nanofibrous membranes. (B and C) Water contact angle of drug-eluting membranes. (D) Bare metal stent. (E) Nanofiber mounted on stent. (F) Balloon inflation at $8 \mathrm{~atm}$. (G) Bare metal stent with nanofibrous membrane (scale bars $=20 \mathrm{~mm}$ ).

that were loaded with sirolimus-eluting biodegradable nanofibers in the descending abdominal aorta of rabbits.

At 1 month, re-endothelialization onto the surfaces of struts differed between the two groups: coverage was significantly greater in the ticagrelor-eluting group (high dose) $(96.4 \% \pm 2.1 \%)$ than in the sirolimus group $(89.0 \% \pm 2.6 \%)$ $(P<0.001)$. The endothelial-dependent vasodilatory response to Ach was also assessed following 4 weeks of stent implantation. Endothelial function was significantly greater in the ticagrelor-eluting group than in the sirolimus-eluting group $(P<0.001)$ (Figure 5).

\section{Histological examination and detection of HES5}

The histological examination and detection of HES5 were completed 4 weeks after the animals responded to injury.

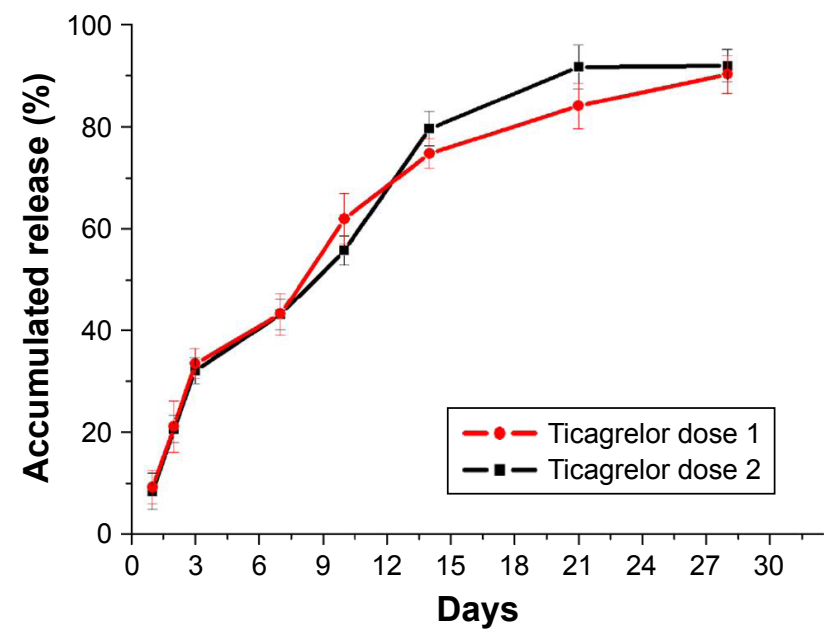

Figure 3 In vitro ticagrelor accumulated release curve.
By 4 weeks, an anatomically intact endothelium had been nearly fully re-constituted, and no intimal hyperplasia or inflammation response was observed in either group. However, the ticagrelor group (Figure 6A, red arrows) exhibited a more complete lining of endothelial cells than that which lined the sirolimus group (Figure 6B, red arrows).

Immunofluorescent labeling of HES5, an SMC proliferation marker, was completed near stented arteries, and observations were made using confocal fluorescence microscopy (Figure 6C-J). The specimens were co-stained with DAPI to reveal cell nuclei (Figure 6I-J). The HES5 labeling index of the interstitials of the intima and the elastic lamina of the aorta was measured as the ratio of the density of the staining of HES5 to that of the DAPI-labeled nuclei. Less HES5-positive labeling was found near the ticagrelor-eluting stented vessels $(0.33 \pm 0.12)$ than close to the sirolimus-eluting stented vessels $(0.57 \pm 0.15)(P<0.05)$. Additionally, the amount of formed neointima suggested that the proliferation of SMCs in the media was lower in the ticagrelor group (Figure 6C and D: merged image, white double arrow).

\section{Local expression of SODI}

Four weeks after deployment, the ticagrelor-eluting stent exhibited up-regulated local expression of SOD1 in the stenting area $(P<0.001)$ (Figure 7$)$.

\section{Discussion}

In this work, biodegradable ticagrelor-eluting nanofibers were developed from electrospun PLGA materials. In vitro and in vivo analyses of the hybrid drug-eluting stent/PLGA nanofiber demonstrated the local and sustained ticagrelor delivery. The effectiveness of hybrid stents in recovering 

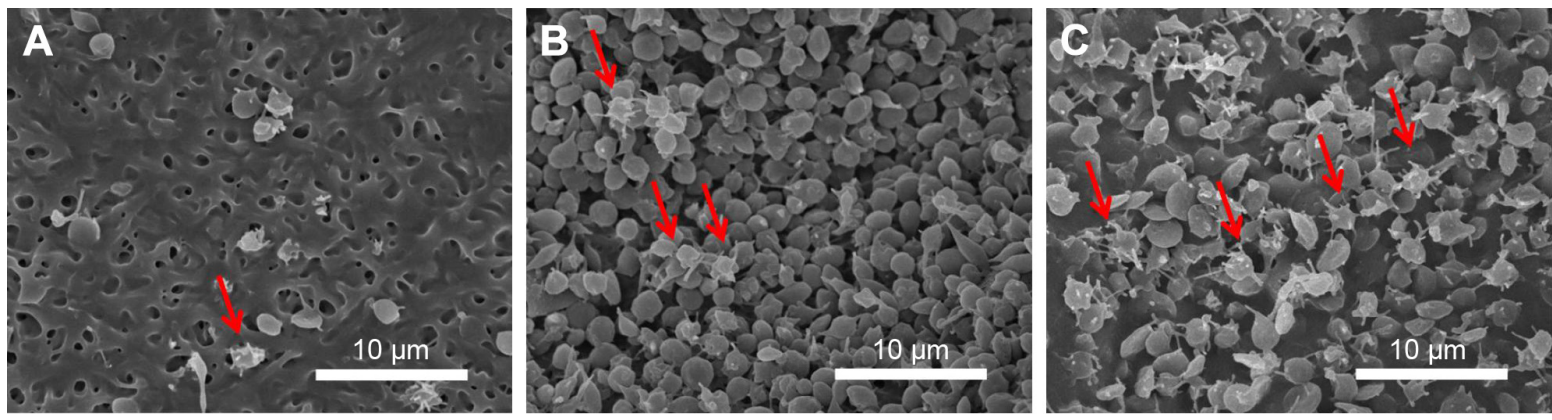

Figure 4 (A) Dose I ticagrelor. (B) Dose 2 ticagrelor. (C) Non-drug eluting nanofiber. Notes: Red arrows indicate activated platelets (scale bars $=10 \mu \mathrm{m}$ ). Magnification 3,000x.

endothelial function and inhibiting the proliferation of SMCs was verified. Released ticagrelor was shown to promote the critical protective potency of functional endothelium and to suppress the proliferation of SMCs.

\section{Characteristics of nanofibers with a ticagrelor loading}

Both topographic and chemical characteristics of the polymer surface affected the proliferation and spreading of cells on it. ${ }^{36}$ The nearby extracellular matrix (ECM) affects endothelium cells more than other cells because of the smaller amount of the endothelial ECM. ${ }^{37}$ Providing a useful matrix for binding enables surrounding endothelial cells to undergo the tubular migration and assembly. Aside from polymeric topographical structures, the wettability of nanofibrous matrix affects the migration and adherence of endothelial cells to the nanofiber because these materials are hydrophobic. ${ }^{38}$ Mixing with other materials reduces contact angles and improves the attachment of cells to hydrophobic polymers because of improved surface wettability ${ }^{39}$ The rate of deformation of fabricated drug-eluting polymer determines the transient elastic deformation and the degree of macromolecule extension. The extensive process continues until the transition of polymeric connection to the rubber-like status in place of the phase coil-stretch of macromolecules in their inherent elastic deformations. ${ }^{40}$ Nanofibers with a higher ticagrelor loading thus showed more hydrophilic characteristics and more extensive profiles of elongation during balloon inflation than low ticagrelor one.

\section{Release kinetics of ticagrelor}

The release kinetics of ticagrelor from the PLGA nanofibers exhibited two stages - an initial burst and a degradationdominated release. For two decades, PLGA has been among the most favorable materials for fabricating devices for use in tissue engineering and drug delivery ${ }^{41}$ Biodegradation of PLGA copolymer by hydrolysis following cleavage of the backbone ester linkages with oligomers and monomers is well known as an effective means of delivering numerous pharmaceuticals. ${ }^{42}$ The process of electrospinning causes drugs to be distributed and stored among the nanofibers. However, a small amount of the drugs may be localized on the nanofibrous surface, leading to the initial burst. Thereafter, polymer degradation controls drug-release. Additionally,
A

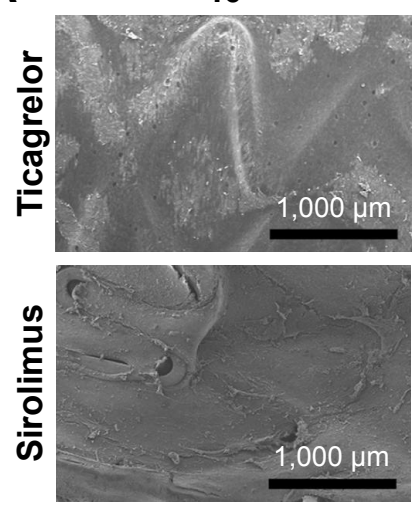

$200 x$

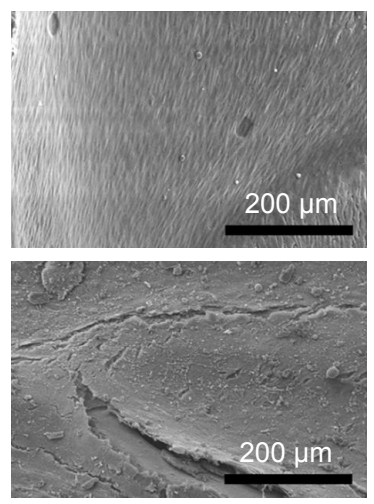

B

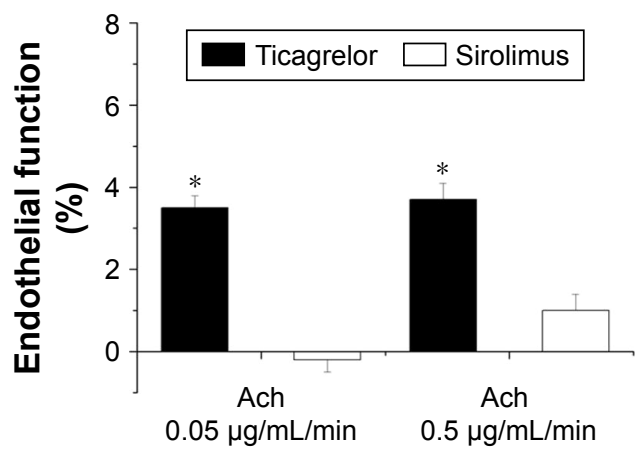

Figure 5 (A) SEM images of endothelial coverage and (B) acetylcystine infusion for endothelial function test $(40 \times:$ scale bar $=1,000 \mu \mathrm{m} ; 200 \times:$ scale bar $=200 \mu \mathrm{m})$. Note: $* P<0.001$.

Abbreviations: Ach, acetylcholine; SEM, scanning electron microscope. 

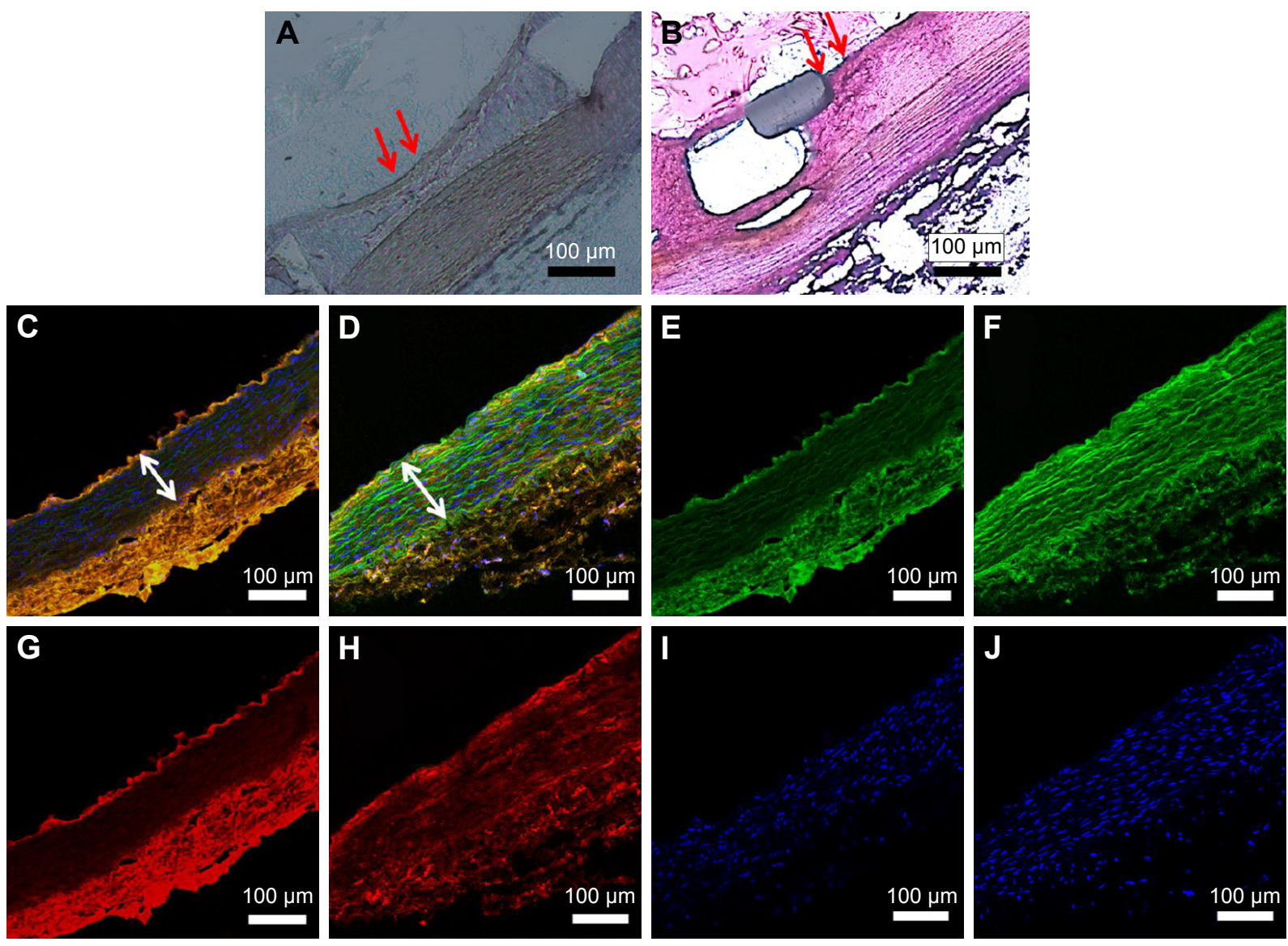

Figure 6 Pathological sections of arterial lesions in two groups, stained by hematoxylin-eosin and HES5 markers at 4 weeks following stent implantation.

Notes: (A) The ticagrelor group (red arrows) exhibited a more complete lining of endothelial cells than the sirolimus group (B, red arrows). Based on confocal fluorescence microscopy, the amount of formed neointima suggests that the proliferation of SMCs in the media was lower in the ticagrelor group (C and $\mathbf{D}$ : merged image, white double arrow). Autofluorescence was observed on the tunica media (E and F; green) and immunofluorescent labeling of HES5 (G and $\mathbf{H}$; orange); a smooth muscle proliferation marker was noted close to the stented arteries, and observations were made using confocal fluorescence microscopy (C-J). The specimens were co-stained with DAPI to reveal cell nuclei (I-J).

Abbreviation: SMC, smooth muscle.

Tica

\section{SOD1}

\section{GAPDH}

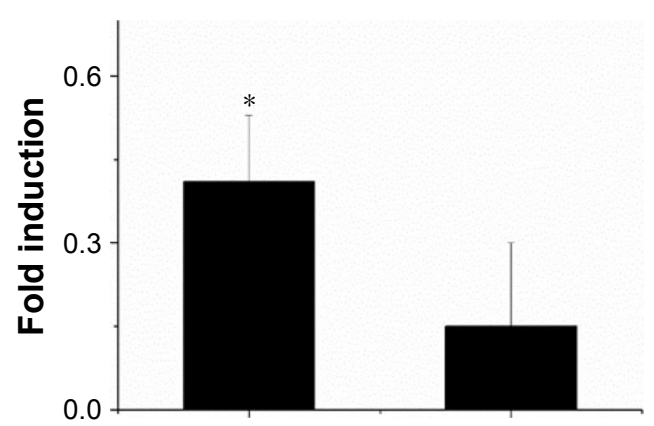

Figure 7 Western blot for SODI.

Note: Four weeks following deployment, the ticagrelor-eluting stent exhibited more up-regulated local expression of SODI in the stenting area than in the sirolimus group $(* P<0.00 I)$.

Abbreviations: SODI, superoxide dismutase I; Siro, Sirolimus; Tica, Ticagrelor. when the speed of water penetration is greater than the polymer degradation rate, the polymers are degraded primarily through the uniform bulk of the matrix. ${ }^{41}$ The drugs are delivered over time as the polymers degrade. The ticagrelor-eluting nanofibers thus exhibited a decelerating and stable release. The hybrid drug-eluting stents that are developed herein can provide local and sustained delivery of high concentrations of ticagrelor in vitro and in vivo for 4 weeks.

\section{Effects of ticagrelor on endothelial regeneration and SMCs inhibition}

The effect of ticagrelor on endothelial regeneration in antiplatelet treatment may involve the pleiotropic function of the treatment. ${ }^{43}$ The interaction of ticagrelor and platelets may affect hemostasis and thrombosis, tissue repair and inflammation either directly or through paracrine mechanisms that involve other circulating blood cells. ${ }^{44}$ Importantly, 
the interaction of circulating progenitor cells with platelets plays a significant role in vascular homeostasis, including differentiation mobilization, chemotaxis, and adhesion. ${ }^{45}$ Evidence of this interplay between progenitor cells and platelets suggests that antiplatelet treatment may influence endothelial repair. ${ }^{46}$ Therefore, ticagrelor-eluting stents favor endothelial recovery and function much more than do sirolimus-eluting stents.

Since adult vascular SMCs are not totally differentiated, cell-matrix signaling, exogenous stimuli, and cell-cell interaction are responsible for the modulation of their phenotype.$^{47} \mathrm{Li}$ et al demonstrated the coordinated regulation of HES5 effector expression in vascular SMC proliferation. ${ }^{48}$ Ticagrelor is known to be linked with the inhibition of SMC proliferation and, thus, reduced neointimal hyperplasia. ${ }^{49-51}$ The results of this study further provide evidence of ticagrelor's beneficial inhibition of neointimal hyperplasia and preservation of endothelialization.

\section{SODI signal}

Tribble et $\mathrm{al}^{52}$ and Liu et $\mathrm{al}^{53}$ found that an elevated level of SOD1 to protect endothelium from the release of NO also protects against acute or chronic oxidative injury during the build-up of fatty material in atherosclerosis. Studies of SOD1 knockout mice have also demonstrated increased expressions of vascular superoxide and peroxynitrite, augmented vasoconstrictor responses, increased myogenic tone, and compromised endothelium-dependent (NO-mediated) relaxation in both large arteries and microvessels. ${ }^{54}$ Oxidative changes of arterial cells and lipoproteins have also been associated with atherogenesis. ${ }^{55}$ Therefore, ticagrelor-eluting stents not only lessen vasoconstrictor responses, but also augment NO-mediated vaso-relaxation.

\section{Study limitations}

Although the use of sirolimus-eluting stents has had consistent effects in clinical trials, ${ }^{56,57}$ the release behavior in vitro affects their efficiency in vivo and the amounts of sirolimus released should be quantified. Moreover, based on our other investigations, control of a stent without drug loading increases the proliferation of SMCs and significantly delays reendothelization. ${ }^{58-60}$ At long-term follow-up, clinical outcomes were significantly better with everolimus-treated than with sirolimus-treated patients, largely due to a lower risk of very late stent thrombosis. ${ }^{61,62}$ Therefore, in the future, everolimus-loaded and non-drug-loaded stents may be used in a control group to develop a more precise methodology.

\section{Conclusion}

This work demonstrated that the sustained and local delivery of ticagrelor via hybrid biodegradable nanofibers/stents reduces neointimal formation and endothelial dysfunction. The ticagrelor-eluting stent substantially preserved endothelial function and re-endothelialization, minimized inflammatory responses, and inhibited neointimal hyperplasia. The further development of ticagrelor-eluting stents may provide an alternative route for treating patients at high risk of bleeding by preserving endothelial recovery and reducing smooth muscle proliferation.

\section{Highlights}

- Effective ticagrelor levels were maintained in vivo for 4 weeks.

- Ticagrelor-eluting stents favor endothelial recovery and function much more than sirolimus-eluting stents.

- Ticagrelor-eluting stents not only lessen vasoconstrictor responses, but also augment NO-mediated vasorelaxation.

\section{Acknowledgments}

The authors would like to thank the Ministry of Science and Technology, Taiwan (Contract No NSC-102-2314-B182A-109) and Chang Gung Memorial Hospital (Contract No CMRPG3F0891) for financially supporting this research. The editorial assistance of the Ted Knoy group is greatly appreciated.

\section{Disclosure}

The authors report no conflicts of interest in this work.

\section{References}

1. Gouëffic Y, Potter-Perigo S, Chan CK, et al. Sirolimus blocks the accumulation of hyaluronan (HA) by arterial smooth muscle cells and reduces monocyte adhesion to the ECM. Atherosclerosis. 2007; 195(1):23-30.

2. Park J, Ha H, Ahn HJ, et al. Sirolimus inhibits platelet-derived growth factor-induced collagen synthesis in rat vascular smooth muscle cells. Transplant Proc. 2005;37(8):3459-3462.

3. Joner M, Finn AV, Farb A, et al. Pathology of drug-eluting stents in humans: delayed healing and late thrombotic risk. $\mathrm{J} \mathrm{Am} \mathrm{Coll} \mathrm{Cardiol.}$ 2006;48(1):193-202.

4. Loh JP, Torguson R, Pendyala LK, et al. Impact of early versus late clopidogrel discontinuation on stent thrombosis following percutaneous coronary intervention with first- and second-generation drug-eluting stents. Am J Cardiol. 2014;113(12):1968-1976.

5. Brodie B, Pokharel Y, Garg A, et al. Predictors of early, late, and very late stent thrombosis after primary percutaneous coronary intervention with bare-metal and drug-eluting stents for ST-segment elevation myocardial infarction. JACC Cardiovasc Interv. 2012;5(10):1043-1051.

6. Wilson GJ, Nakazawa G, Schwartz RS, et al. Comparison of inflammatory response after implantation of sirolimus- and paclitaxel-eluting stents in porcine coronary arteries. Circulation. 2009;120(2):141-149. 
7. Husted S, van Giezen JJ. Ticagrelor: the first reversibly binding oral P2Y12 receptor antagonist. Cardiovasc Ther. 2009;27(4):259-274.

8. Sürer S, Toktas F, Ay D, et al. Effect of the P2Y12 antagonist ticagrelor on neointimal hyperplasia in a rabbit carotid anastomosis model. Interact Cardiovasc Thorac Surg. 2014;19(2):198-204.

9. Torngren K, Ohman J, Salmi H, Larsson J, Erlinge D. Ticagrelor improves peripheral arterial function in patients with a previous acute coronary syndrome. Cardiology. 2013;124(4):252-258.

10. Patil SB, Jackman LE, Francis SE, Judge HM, Nylander S, Storey RF. Ticagrelor effectively and reversibly blocks murine platelet P2Y12mediated thrombosis and demonstrates a requirement for sustained P2Y12 inhibition to prevent subsequent neointima. Arterioscler Thromb Vasc Biol. 2010;30(12):2385-2391.

11. Oh M, Lee CW, Lee HS, et al. Similar impact of clopidogrel or ticagrelor on carotid atherosclerotic plaque inflammation. Clin Cardiol. 2016;39(11):646-652.

12. Teng R, Oliver S, Hayes MA, Butler K, Absorption BK. Absorption, distribution, metabolism, and excretion of ticagrelor in healthy subjects. Drug Metab Dispos. 2010;38(9):1514-1521.

13. Becker RC, Bassand JP, Budaj A, et al. Bleeding complications with the P2Y12 receptor antagonists clopidogrel and ticagrelor in the PLATelet inhibition and patient Outcomes (PLATO) trial. Eur Heart J. 2011;32(23):2933-2944.

14. Lu L, Peter SJ, Lyman MD, et al. In vitro and in vivo degradation of porous poly(DL-lactic-co-glycolic acid) foams. Biomaterials. 2000; 21(18):1837-1845.

15. Kumbar SG, Nukavarapu SP, James R, Nair LS, Laurencin CT, Poly E. Electrospun poly(lactic acid-co-glycolic acid) scaffolds for skin tissue engineering. Biomaterials. 2008;29(30):4100-4107.

16. Ali SA, Doherty PJ, Williams DF. Mechanisms of polymer degradation in implantable devices. 2. Poly(DL-lactic acid). J Biomed Mater Res. 1993;27(11):1409-1418.

17. Wessely R. New drug-eluting stent concepts. Nat Rev Cardiol. 2010; 7(4):194-203.

18. Byrne RA, Kastrati A, Kufner S, et al. Randomized, non-inferiority trial of three limus agent-eluting stents with different polymer coatings: the Intracoronary Stenting and Angiographic Results: Test Efficacy of 3 Limus-Eluting Stents (ISAR-TEST-4) Trial. Eur Heart J. 2009; 30(20):2441-2449.

19. Windecker S, Serruys PW, Wandel S, et al. Biolimus-eluting stent with biodegradable polymer versus sirolimus-eluting stent with durable polymer for coronary revascularisation (LEADERS): a randomised non-inferiority trial. Lancet. 2008;372(9644):1163-1173.

20. Serruys PW, Regar E, Carter AJ. Rapamycin eluting stent: the onset of a new era in interventional cardiology. Heart. 2002;87(4):305-307.

21. Teo WE, Ramakrishna S. A review on electrospinning design and nanofibre assemblies. Nanotechnology. 2006;17(14):R89-R106.

22. Dutt O, Ashton H. PVC roofing membranes: Factors affecting tensile tests. Ottawa, Canada: National Research Council Canada; 1985.

23. Lee $\mathrm{CH}$, Chang SH, Chen WJ, et al. Augmentation of diabetic wound healing and enhancement of collagen content using nanofibrous glucophage-loaded collagen/PLGA scaffold membranes. $J$ Colloid Interface Sci. 2015;439:88-97.

24. Kalyani L, Lakshmana Rao A. A validated stability-indicating HPLC method for determination of ticagrelor in bulk and its formulation. Int J Pharm. 2013;3:634-642.

25. Kukreja N, Onuma Y, Daemen J, Serruys PW. The future of drug-eluting stents. Pharmacol Res. 2008;57(3):171-180.

26. Hedenqvist P. Anaesthesia and analgesia for surgery in rabbits and rats: a comparison of the effects of different compounds. Stockholm, Sweden: Karolinska Institute, Department of Physiology and Pharmacology; 2008.

27. Phinikaridou A, Hua N, Pham T, Hamilton JA. Regions of low endothelial shear stress colocalize with positive vascular remodeling and atherosclerotic plaque disruption: an in vivo magnetic resonance imaging study. Circ Cardiovasc Imaging. 2013;6(2):302-310.
28. Masuo O, Terada T, Walker G, et al. Study of the patency of small arterial branches after stent placement with an experimental in vivo model. AJNR Am J Neuroradiol. 2002;23(4):706-710.

29. Tanaka H, Sukhova GK, Swanson SJ, et al. Sustained activation of vascular cells and leukocytes in the rabbit aorta after balloon injury. Circulation. 1993;88(4 Pt 1):1788-1803.

30. Tanaka H, Sukhova G, Schwartz D, Libby P. Proliferating arterial smooth muscle cells after balloon injury express TNF-alpha but not interleukin-1 or basic fibroblast growth factor. Arterioscler Thromb Vasc Biol. 1996; 16(1):12-18.

31. Lee $\mathrm{C}-\mathrm{H}$, Chang $\mathrm{S}-\mathrm{H}$, Lin $\mathrm{Y}-\mathrm{H}$, et al. Acceleration of re-endothelialization and inhibition of neointimal formation using hybrid biodegradable nanofibrous rosuvastatin-loaded stents. Biomaterials. 2014;35(15): 4417-4427.

32. Drolet MC, Plante E, Battistini B, Couet J, Arsenault M. Early endothelial dysfunction in cholesterol-fed rabbits: a non-invasive in vivo ultrasound study. Cardiovasc Ultrasound. 2004;2:10.

33. Nakazawa G, Granada JF, Alviar CL, et al. Anti-CD34 antibodies immobilized on the surface of sirolimus-eluting stents enhance stent endothelialization. JACC Cardiovasc Interv. 2010;3(1):68-75.

34. Kornowski R, Hong MK, Tio FO, Bramwell O, Wu H, Leon MB. In-stent restenosis: contributions of inflammatory responses and arterial injury to neointimal hyperplasia. J Am Coll Cardiol. 1998;31(1):224-230.

35. Schwartz RS, Huber KC, Murphy JG, et al. Restenosis and the proportional neointimal response to coronary artery injury: results in a porcine model. J Am Coll Cardiol. 1992;19(2):267-274.

36. Laco F, Grant MH, Black RA. Collagen-nanofiber hydrogel composites promote contact guidance of human lymphatic microvascular endothelial cells and directed capillary tube formation. J Biomed Mater Res A. 2013;101(6):1787-1799.

37. Farnsworth RH, Achen MG, Stacker SA. Lymphatic endothelium: an important interactive surface for malignant cells. Pulm Pharmacol Ther. 2006; 19(1):51-60.

38. Arima Y, Iwata H. Effect of wettability and surface functional groups on protein adsorption and cell adhesion using well-defined mixed selfassembled monolayers. Biomaterials. 2007;28(20):3074-3082.

39. Lee SJ, Khang G, Lee YM, Lee HB. Interaction of human chondrocytes and NIH/3T3 fibroblasts on chloric acid-treated biodegradable polymer surfaces. J Biomater Sci Polym Ed. 2002;13(2):197-212.

40. Malkin AY, Arinstein A, Kulichikhin VG. Polymer extension flows and instabilities. Prog Polym Sci. 2014;39(5):959-978.

41. Makadia HK, Siegel SJ. Poly Lactic-co-glycolic acid (PLGA) as biodegradable controlled drug delivery carrier. Polymers. 2011;3(3):1377-1397.

42. Ramchandani M, Robinson D. In vitro and in vivo release of ciprofloxacin from PLGA 50:50 implants. J Control Release. 1998;54(2):167-175.

43. Bonello L, Frere C, Cointe S, et al. Ticagrelor increases endothelial progenitor cell level compared to clopidogrel in acute coronary syndromes: a prospective randomized study. Int J Cardiol. 2015;187:502-507.

44. Davì G, Patrono C. Platelet activation and atherothrombosis. $N$ Engl J Med. 2007;357(24):2482-2494.

45. Sopova K, Tatsidou P, Stellos K. Platelets and platelet interaction with progenitor cells in vascular homeostasis and inflammation. Curr Vasc Pharmacol. 2012;10(5):555-562.

46. Vieira-de-Abreu A, Campbell RA, Weyrich AS, Zimmerman GA. Platelets: versatile effector cells in hemostasis, inflammation, and the immune continuum. Semin Immunopathol. 2012;34(1):5-30.

47. Owens GK, Kumar MS, Wamhoff BR. Molecular regulation of vascular smooth muscle cell differentiation in development and disease. Physiol Rev. 2004;84(3):767-801.

48. Li X, Zhang X, Leathers R, et al. Notch3 signaling promotes the development of pulmonary arterial hypertension. Nat Med. 2009;15(11): 1289-1297.

49. Steg PG, Harrington RA, Emanuelsson H, et al. Stent thrombosis with ticagrelor versus clopidogrel in patients with acute coronary syndromes: an analysis from the prospective, randomized PLATO trial. Circulation. 2013;128(10):1055-1065. 
50. Kim HK, Jeong MH, Lim KS, et al. Effects of ticagrelor on neointimal hyperplasia and endothelial function, compared with clopidogrel and prasugrel, in a porcine coronary stent restenosis model. Int J Cardiol. 2017;240:326-331.

51. Preusch MR, Rusnak J, Staudacher K, et al. Ticagrelor promotes atherosclerotic plaque stability in a mouse model of advanced atherosclerosis. Drug Des Devel Ther. 2016;10:2691-2699.

52. Tribble DL, Barcellos-Hoff MH, Chu BM, Gong EL. Ionizing radiation accelerates aortic lesion formation in fat-fed mice via SOD-inhibitable processes. Arterioscler Thromb Vasc Biol. 1999;19(6):1387-1392.

53. Liu JQ, Zelko IN, Folz RJ. Reoxygenation-induced constriction in murine coronary arteries: the role of endothelial NADPH oxidase (gp91phox) and intracellular superoxide. J Biol Chem. 2004;279(23): 24493-24497.

54. Didion SP, Ryan MJ, Didion LA, Fegan PE, Sigmund CD, Faraci FM. Increased superoxide and vascular dysfunction in CuZnSOD-deficient mice. Circ Res. 2002;91(10):938-944.

55. Stocker R, Keaney JF. Role of oxidative modifications in atherosclerosis. Physiol Rev. 2004;84(4):1381-1478.

56. Moses JW, Leon MB, Popma JJ, et al. Sirolimus-eluting stents versus standard stents in patients with stenosis in a native coronary artery. N Engl J Med. 2003;349(14):1315-1323.
57. Wessely R, Schömig A, Kastrati A. Sirolimus and paclitaxel on polymerbased drug-eluting stents: similar but different. J Am Coll Cardiol. 2006; 47(4):708-714.

58. Chang SH, Lee $\mathrm{CH}$, Yeh YH, et al. Propylthiouracil-coated biodegradable polymer inhibited neointimal formation and enhanced re-endothelialization after vascular injury. Int J Nanomedicine. 2018; $13: 13$.

59. Lee $\mathrm{CH}$, Lin $\mathrm{YH}$, Chang SH, et al. Local sustained delivery of acetylsalicylic acid via hybrid stent with biodegradable nanofibers reduces adhesion of blood cells and promotes reendothelialization of the denuded artery. Int J Nanomedicine. 2014;9:311.

60. Lee $\mathrm{CH}$, Chang SH, Lin YH, et al. Acceleration of re-endothelialization and inhibition of neointimal formation using hybrid biodegradable nanofibrous rosuvastatin-loaded stents. Biomaterials. 2014;35(15): 4417-4427.

61. Räber L, Jüni P, Nüesch E, et al. Long-term comparison of everolimuseluting and sirolimus-eluting stents for coronary revascularization. J Am Coll Cardiol. 2011;57(21):2143-2151.

62. Jensen LO, Thayssen P, Christiansen EH, et al. Safety and efficacy of everolimus- versus sirolimus-eluting stents: 5-year results from SORT OUT IV. J Am Coll Cardiol. 2016;67(7):751-762.
International Journal of Nanomedicine

\section{Publish your work in this journal}

The International Journal of Nanomedicine is an international, peerreviewed journal focusing on the application of nanotechnology in diagnostics, therapeutics, and drug delivery systems throughout the biomedical field. This journal is indexed on PubMed Central, MedLine, CAS, SciSearch $®$, Current Contents ${ }^{\circledR} /$ Clinical Medicine,

\section{Dovepress}

Journal Citation Reports/Science Edition, EMBase, Scopus and the Elsevier Bibliographic databases. The manuscript management system is completely online and includes a very quick and fair peer-review system, which is all easy to use. Visit http://www.dovepress.com/ testimonials.php to read real quotes from published authors. 